\title{
Autosimilarty, Long Memory and Chaos: Evidence from the Tunisian Market
}

\author{
Monia Antar Limam \\ Correspondence: Monia Antar Limam, Assistant Professor, Carthage University, ISCCB, Tunisia.
}

Received: March 6, 2017

doi:10.11114/bms.v3i2.2449

\author{
Accepted: May 30, 2017 \\ Online Published: May 31, 2017 \\ URL: https://doi.org/10.11114/bms.v3i2.2449
}

\begin{abstract}
Fractal Finance came to the rescue of the classical models unable to explain financial anomalies and of linear models inadequate to characterize complex processes. The characterization of financial series is still topical. The calculation of the Hurst exponent, the fractal dimension, the Lyapunov exponent, the window of Theiler and the realization of the determinism test, have allowed us to understand the dynamics of the Tunisian indexes returns. Clearly, findings show that the returns are, on the one hand, nonlinear, follow alpha-stable laws, have a long memory and on the other hand, are not chaotic. Thus, the hypothesis of a Brownian fractal motion is privileged.
\end{abstract}

Keywords: Tunisian, finance, market

\section{Introduction}

This article provides not only a review of criticisms made to the assumptions of the orthodox financial models but also, attempts to verify the existence of a chaotic behaviour on the returns of the Tunisian stock market Indexes. If this is the case, therefore the process is non-linear, sensitive to initial conditions and characterized by the presence of a specific attractor $^{1}$ El Haddad (2016).

In fact, chaos theory allows for order in disorder. This theory originates in the rejection of both the efficiency hypothesis and the irrational behaviour of investors. In classical theory, shocks allow price changes, whereas in a chaotic process, wild changes are integral part of the process.

At this level, the literature is divided. There are those who support the existence of a deterministic chaos, like Ryane (2015) on the Moroccan Stock Exchange, Lin (2014) on the Swedish stock exchange, Blank (1991) on the S \& P500 and Hacinliyan and Kandiran (2015) on the Turkish stock exchange.

Others are against it for example Girerd-Potin (1994) on the French SBF, El Haddad (2016) on the Casablanca market, McKenzie (2001) on the main indexes of 10 countries including Germany, France, Switzerland and Hong Kong. Similarly, in a review article Sewell (2008) concluded that the use of chaos theory outside physics is inappropriate and concludes on the basis of 21 articles, the existence of weak evidence of chaos on financial markets. Hołyst et al (2001) presented a mixed result in concluding that the actual economic dynamics is a mixture of deterministic chaos and stochastic.

This article verifies the followings: the non-normality, the nonlinearity, and the existence of a fractal structure as well as a chaotic process on indexes returns on the Tunisian Stock Exchange.

\section{Classical Finance and Reconsideration of Its Assumptions}

The fundamental value is the first concept brought to explain risk. The slogan was "because". We are more gifted to explain than to understand and we feel more intelligent while explaining retrospectively than accepting risk. Then, the technical analysis appeared. A financial astrology, that can work from time to time, but cannot be considered as a risk management tool. Then, the idea of random walk from Bachelor thesis will structure the modern finance. We cannot predict whether prices will go up or down but we can know the extent of this variation. Later on, Fama discovered that the expected profit of a speculator is zero and introduced the efficient market hypothesis. The system produced its first inconsistency by Grossamn and Stiglitz paradox in 1980. With portfolio theory, Markowitz introduced the risk return trade off and shed the light on the correlations among assets. The major drawback of the model is that it requires a lot of

${ }^{1}[1]$ attractor is a geometrical form towards which converges all the trajectories of the dynamic system. 
computation. This will be quickly restored with the one factor model of William Sharpe. Each asset has its beta; we no longer evaluate each asset by comparing it to all others but to the market! The CAPM is rewarded by a Nobel Prize in 1990. An important innovation comes with the introduction of APT by Ross in 1976. There several beta and we can integrate as many factors as desired. In addition, the famous Black and Scholes model allows us to speculate on the volatility and open the way to the financial engineering. It is the reign of Finance. Finally, do not forget, B \& S model is correct only when you assume the relevance of the bell curve to properly describe data, the rigor of the variance as a risk measure and the independently distributed returns Mandelbrot (2009). Everything goes for the best til the 1987 crash. A very unlikely event according to academics, its probability is one out of zillion. Other financial turbulence followed in the 1990s, and variations of more than 25 standard deviations were observed! Something goes wrong. Errors in the models? Old theories are no longer respected. We are looking for new ideas and all discrepancies with the CAPM are called anomalies. In 1992, Fama and French announce the death of Beta and present the three factors model. We improve things but we are still beyond the Gaussian framework. Similarly, when it is clear that volatility is not constant as recommended in the standard financial literature and focuses on certain time intervals, we look for new models allowing kurtosis to exceed 3. Instead of rejecting the bell curve, we will arrange it. In the 80's, Engle developed the GARCH model and received the Nobel Prize in 2003. What is more, the bankruptcy in 1998 of LTCM $^{2}$. A hedge fund managed by Scholes and Merton just one year after the two professors received Nobel Prize. In fact, there is no doubt that the base of finance is to review. We shall begin by reviewing the assumptions that underlie it. The homo economicus rationality is strongly criticized. With the development of the perspective theory, Kanheman and Tversky have organized all the exceptions to the vNM axioms and have tried to model the individual behaviour. The homogeneity is also to reject. Indeed, investors are very different. Pension funds can keep their assets during decades whereas other investors liquidate their position at latest within a day. Then, saying variations are i.i.d, this of course presupposes independence, stationarity and normality of variations. First, the independence means that in addition to having small and kind variations, each fluctuation is independent from the previous one. Second, stationnarity assumes that the process generating price variations remains unchanged over time. Third, the normal distribution of changes relates to the fact that most of the observed fluctuations oscillate around the average, deviation probabilities decrease exponentially as we move from the average. The aberrations become more and more unlikely. The traditional Gaussian worldview begins to focus on the ordinary, then deals with exceptions or aberrations. However, there is another way to proceed: take the exceptional as a point of departure and consider the ordinary as secondary Taleb (2008).

If a single phenomenon observed is sufficient to refute the Gaussian system, millions of others could not confirm its application validity. The bell curve does not allow significant variances but other alternative tools do not prohibit the long periods of dead calm.

\section{Benign and Wild Random}

In his prophetic book "fractal approach of markets", Mandelbrot enlightens us on the nature of risk. According to the author, the dice roll at random, the roulette wheel spins at random but not the increase or decrease of assets. While studying cotton prices from 1916 until 2003, we notice that he introduced the wild random. Indeed, "The theory predicts 6 days where the index would vary more than 4.5\%; in reality, there were 366". Mandelbrot described the wild random as an arrow throwing; whereas coin flips would be a benign form of chance. The first belongs to Cauchy world and is completely different from the second, which can be described by the Gaussian world. For a blindfolded archer the most distant shots are as large as the sum of all the others. A score in a blind archery never stabilizes around a predictable mean. Errors do not converge and have infinite mean and infinite variance. The extremes of Gauss and Cauchy reflect two extreme worldviews. In the first, major changes are the result of a large number of small, while in the second isolated and major events appear abnormally important. Like Mandelbrot, Taleb draws up two areas. The first is called Mediocristan. This is a domain that science can understand, where the exception is not dominant. It is a quiet province where nothing ever happens, where one must undergo the tyranny of the collective and the routine. The second area is named the extremistan where random is wild. It is the place where one must undergo the tyranny of the singular, the unexpected. The extremistan is scalable ${ }^{3}$. It is a province generating black swans ${ }^{4}$ and the inequalities are such a single phenomenon can have a disproportionate impact on the whole 5 .

\footnotetext{
${ }^{2}$ Long Term Capital Management is an hedge fund created in 1994.

${ }^{3}$ According to Taleb (2010), a scalable job is not remunerated on a time basis i.e. without rates of pay. On the other hand, the life expectancy is not scalable since the more one ages, the closer death is. For more detail see Finance : le nouveau paradigme (Herlin (2010)).
}

${ }^{4}$ Events highly improbable with deep consequences .

${ }^{5}$ Bill Gates is richer than a billion of poor people 


\section{Normal Law vs Power Law}

The power laws had been detected by Vilfredo Pareto, who had discovered that could been applied to the income distribution. He has grouped people by slices of income, and for each tranche, he has counted their number and then drawn the result. A line instead of the bell curve appears. The data which vary according to a power law, have this convenient to draw a straight oblique line. The slope of the line is the exponent of the power law. The formula of Pareto is as follows: $P(u)=(u / m)^{-\alpha}$ and allows us to know the proportion of individuals who earn more than a certain level of income $u$. $m$ is the average income. The alpha allows to quantify the unfairness of society. It is estimated to $-3 / 2$. Taleb (2010) argues that the physical phenomena (size, weight) fall under the normal law, while the intangible and virtual phenomena fall under power laws (books sales, asset prices, etc). Herlin (2010) stipulates that what is scalable comes under power laws.

With financial prices, power law means that large fluctuations are as frequent as small ones. This fact is in contrast with normal distribution, since in the later mean-reversion is assured. In fact, financial asset price may be relatively stable for a long period of time then make a high jump and find again a calm period before another jump. The notion of balance is punctual and relative.

Therefore, we propose to verify the adequacy of power laws to Tunisian indexes returns. We have chosen to work on the indexes because fluctuations of individual assets will be compensated between themselves and specific risk will be removed.

\section{Data}

We have collected the data relating to the two main indexes as well as all sectoral indexes quoted on the BVMT. The observation period is heterogeneous relaying on data availability. Table 1 presents descriptive statistics. Only two indexes have negative mean returns namely the insurance (INDAS) and construction \& building materials (INBMC) indexes. Only Tunindex, Banks, financial companies and financial services Indexes have a positive median. The coefficient of variation shows that the food and beverages index is the least risky tracked by consumer goods index. The index of construction and building materials is the most risky. All skweness are different from zero. In addition, all kurtosis are greater than three. This characterize existence of fat tails. Jarque Bera Statistics is significant for all indexes. The normality of price returns is rejected.

This rejection of returns normality can be indicative of returns non-linearity. We have to see whether power laws are really better for describing indexes returns. This table summarizes the descriptive statistics relating to all Tunisian Indexes. For each index, mean, median, standard deviation, coefficient of variation, skewness, kurtosis as well as JB statistics were calculated.

Table 1. Summary statistics

\begin{tabular}{llllllllll}
\hline Indexes & $\begin{array}{l}\text { Starting } \\
\text { period }\end{array}$ & $\mathrm{N}$ & Mean $\%$ & Median $\%$ & $\mathrm{Sd} \%$ & & Skewness & Kurtosis & JB \\
\hline tunin 20 & $02 / 01 / 2012$ & 994 & 0,01232 & $-0,00794$ & 0,49259 & 39,98 & $-0,4109589$ & 10,23158 & $2193,897^{*}$ \\
Tunindex & $30 / 05 / 2008$ & 1879 & 0,02848 & 0,02630 & 0,60177 & 21,13 & $-0,823666$ & 15,44873 & $12345,39^{*}$ \\
INSFI & $30 / 05 / 2008$ & 1879 & 0,03918 & 0,03555 & 0,84821 & 21,65 & $-0,3166772$ & 9,518759 & $3358,349^{*}$ \\
INPMP & $01 / 04 / 2014$ & 437 & 0,04697 & $-0,03766$ & 1,23705 & 26,34 & 0,6401277 & 4,447205 & $67,98^{*}$ \\
INDSF & $30 / 05 / 2008$ & 1879 & 0,03039 & 0,02538 & 0,63732 & 20,97 & $-0,641967$ & 14,42799 & $10353,87^{*}$ \\
INDSC & $30 / 05 / 2008$ & 1879 & 0,02178 & $-0,02837$ & 0,86534 & 39,73 & $-0,1658611$ & 8,053381 & $2007,923 *$ \\
INDMB & $01 / 07 / 2008$ & 1857 & 0,00340 & 0,00000 & 0,86148 & 253,38 & 0,2118289 & 5,530103 & $509,1977^{*}$ \\
INDIN & $30 / 05 / 2008$ & 1879 & 0,01705 & $-0,04815$ & 0,98636 & 57,85 & 0,2901904 & 5,524727 & $525,4224^{*}$ \\
INDDI & $02 / 01 / 2009$ & 1734 & 0,03484 & $-0,02947$ & 0,85888 & 24,65 & 0,0777195 & 7,717527 & $1609,673^{*}$ \\
INDBQ & $30 / 05 / 2008$ & 1879 & 0,02840 & 0,01395 & 0,68221 & 24,02 & $-0,3778632$ & 12,41748 & $6988,32^{*}$ \\
INDAS & $03 / 01 / 2011$ & 1233 & $-0,00982$ & $-0,01017$ & 0,94234 & $-95,96$ & 0,0839409 & 6,469768 & $619,9665^{*}$ \\
INBMC & $30 / 05 / 2008$ & 1879 & $-0,00233$ & $-0,07126$ & 1,13575 & $-487,45$ & 0,332147 & 5,733088 & $619,37^{*}$ \\
INBCO & $30 / 05 / 2008$ & 1879 & 0,04734 & 0,00182 & 0,94911 & 20,05 & 0,2206562 & 7,335655 & $1486,967 *$ \\
INAUE & $30 / 05 / 2008$ & 1879 & 0,01109 & $-0,04331$ & 1,27420 & 114,90 & 0,1873246 & 4,605131 & $212,7033^{*}$ \\
INAAB & $18 / 07 / 2011$ & 1110 & 0,07507 & $-0,01499$ & 1,00786 & 13,43 & 0,3771506 & 6,727844 & $669,0429^{*}$ \\
\hline
\end{tabular}

\section{Parameter Estimation of a Stable Law}

Stable laws are based on Pareto laws, have heavy tails and are characterized by their characteristic function $\varphi x(t)$, which is none other than the expected value (E) and which depends on four parameters. This is a Fourier transform (FT) of the probability density $f$ of the probability distribution of $\mathrm{x}$.

$$
\varphi_{x}(t)=\int f(x) e^{i t x} d x=E\left(e^{i t X}\right) \exp =T F(f)
$$




$$
\left.\mathrm{E}\left(\mathrm{e}^{\mathrm{itX}}\right)=i \delta t-\gamma|t|^{\alpha}\left[1+i \beta\left(\frac{t}{|t|}\right) \tan \left(\frac{\alpha \pi}{2}\right)\right] ; \alpha \in\right] 0,
$$

$\alpha$ is the characteristic exponent of the law. This is the most important parameter that determines tails thickness. In Gaussian law it is equal to 2 . When $\alpha$ is less than 2 , the variance is infinite. $\beta$ is the skewness. The shift parameter is $\delta$ and the scaling parameter $\gamma$ means it determines the total probabilities intensity. Mean is infinite if $\alpha$ is less than 1 . For $\alpha=1$ and $\beta=0$, we obtain Cauchy distribution with very fat tails.

Parameter estimation of a stable law is now possible with several methods. The McCulloch (1986) method is based on percentiles and provides an estimate as a result of reading in Du Mouchel (1971) tables and through a linear interpolation. This method is valid for $\alpha>0.6$.

$$
N_{\alpha}=\frac{x_{0.95}-x_{0.05}}{x_{0.75}-x_{0.25}} \quad N_{\beta}=\frac{x_{0.95}+x_{0.05}-2 x_{0.5}}{x_{0.95}-x_{0.05}}
$$

$N_{\sigma}=\frac{x_{0.75}-x_{0.25}}{\sigma} \quad \hat{\sigma}=\frac{\hat{x}_{0.75}-\hat{x}_{0.25}}{N_{\sigma}}$

$$
\widehat{\mu}=\widehat{G}-\widehat{\beta} \hat{\sigma} \tan \left(\frac{\pi \alpha}{2}\right) \quad \operatorname{avec} \alpha \neq 1 \quad \hat{\mu}=\widehat{G}
$$

$\operatorname{avec} \alpha=1$

Touba (2014) reports that McCulloch method provides good parameters estimators with fast time execution. However, the maximum likelihood method provides much more precise estimates, especially of the skewness. Nevertheless, it remains very costly in execution time. In this article, we present the parameters of a stable alpha law using the two methods mentioned above. The four parameters of an alpha-stable law estimates with the Mc Culoch method (panel to the left) and with the maximum likelihood method (right) for all quoted indexes on the Tunisian Stock Exchange from 30/05/2008 until 31/12/2015.

Table 2. Alpha stable parameters estimates

\begin{tabular}{lllllllll}
\hline \multicolumn{4}{l}{ Mc Culloch Method } & \multicolumn{5}{c}{ Maximum Likelihood Method } \\
\hline Indice & $\hat{\alpha}$ & $\hat{\beta}$ & $\hat{\sigma}$ & $\hat{\mu}$ & $\hat{\alpha}$ & $\hat{\beta}$ & $\hat{\sigma}$ & $\hat{\mu}$ \\
Tunidex20 & 1.675 & 0.329 & 0.0026854879 & -0.000148968 & 1.7115656341 & 0.2865543898 & 0.0027290367 & 0.00010476 \\
Tunindex & 1.609 & 0.101 & 0.0027042887 & 0.0004394086 & 1.5859327929 & 0.0689828751 & 0.0026845506 & 0.00053541 \\
INSFI & 1.526 & 0.162 & 0.0040188245 & 0.0003586248 & 1.5747983094 & 0.1201042291 & 0.0041552486 & 0.00045957 \\
INPMP & 1.323 & 0.171 & 0.0058901936 & -0.000581409 & 1.750890852 & 0.740673282 & 0.007743681 & -0.0014586 \\
INDSF & 1.574 & 0.046 & 0.002901858 & 0.0004329911 & 1.716474 & $-0,0000188$ & 0,0031034 & 0,00018027 \\
INDSC & 1.435 & 0.118 & .0041802333 & -0.000382192 & 1.5742754633 & 0.1575372953 & 0.0045189269 & -0.0001623 \\
INDMB & 1.62 & 0,078 & 0.004959324 & -0.000817252 & 1.7775194425 & 0.1233013573 & 0.0052967332 & -0.0002085 \\
INDIN & 1.496 & 0.253 & 0.0051286644 & -0.000610566 & 1.5709542829 & 0.2553230975 & 0.0052473973 & -0.0004033 \\
INDDI & 1.5 & 0.231 & 0.0043448472 & -0.000485483 & 1.5831666696 & 0.2385173563 & 0.0045308676 & -0.0002591 \\
INDBQ & 1.492 & 0.148 & 0.0031393027 & 0.0001787023 & 1.5890693524 & 0.1332444334 & 0.0033367297 & 0.00039167 \\
INDAS & 1.44 & -0.093 & 0.0046997025 & 0.0001242408 & 1.7269049825 & -0.155265954 & 0.0053950742 & 0.00022240 \\
INBMC & 1.449 & 0.231 & 0.0057302016 & -0.000892757 & 1.5427437939 & 0.2185473613 & 0.0059265020 & -0.0006726 \\
INBCO & 1.387 & 0.17 & 0.0042291135 & -0.000165857 & 1.5062088832 & 0.2110729440 & 0.0045661944 & -0.0001230 \\
INAUE & 1.523 & 0.083 & 0.0070405451 & -0.000289727 & 1.5747983094 & 0.1201042291 & 0.0041552486 & 0.00045957 \\
INAAB & 1.377 & 0.33 & 0.0043829189 & -0.000581637 & 1.4439908472 & 0.3560123228 & 0.0046064716 & -0.0002473 \\
\hline
\end{tabular}

Note first that the two methods gave satisfactory results. The parameter $\alpha$ is less than 2 for all indexes and whatever the method used. This shows that the variance is infinite and tails are thick. We also emphasize that the parameter $\beta$ is higher when it is determined by the maximum likelihood method. In all estimates, we have results different from 1 and -1 i.e. situations where asymmetry is pronounced to the right or the left. The proximity to zero shows the existence of symmetrical distributions. $\mu$ can be an interpreter as the average return of each index.

In order to check the adequacy of the stable law parameters estimates, with the two methods mentioned above, with the empirical distribution of returns, we draw them on the same graph. Furthermore, we have a normal distribution adequately to each index. Figure 1 shows that returns distribution of all indexes are much better represented by a stable law than by a Gaussian law. This argues for the existence of fat tails and rejects normality. To check the suitability of the empirical distribution of returns with the parameters of the stable distribution estimated by the two methods mentioned meadow, we gathered all three on the same graph. Moreover, we have added a proper normal distribution for each index. Examination of Figure 1 shows that the returns are better represented by a stable rather than by a Gaussian law. 

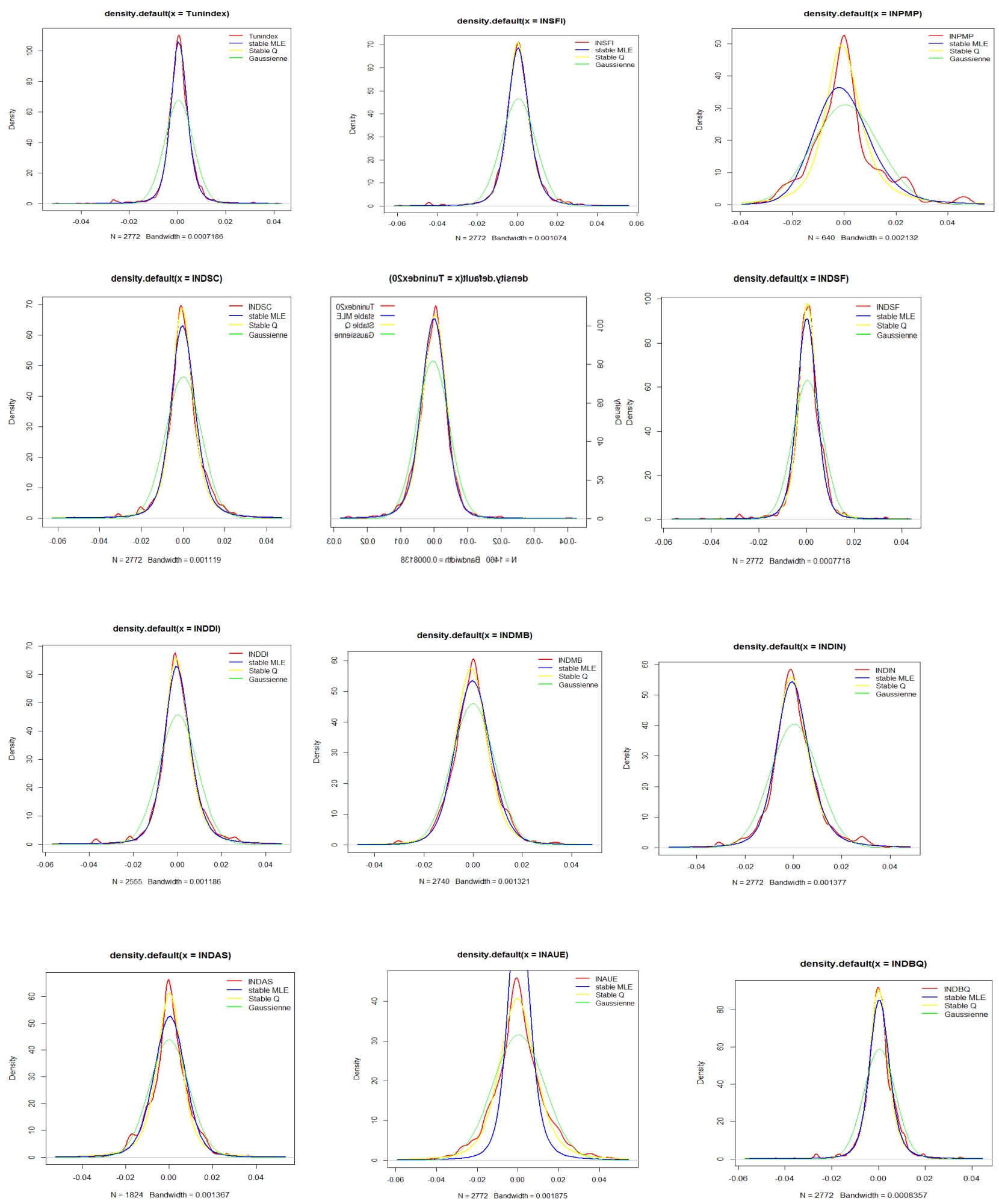

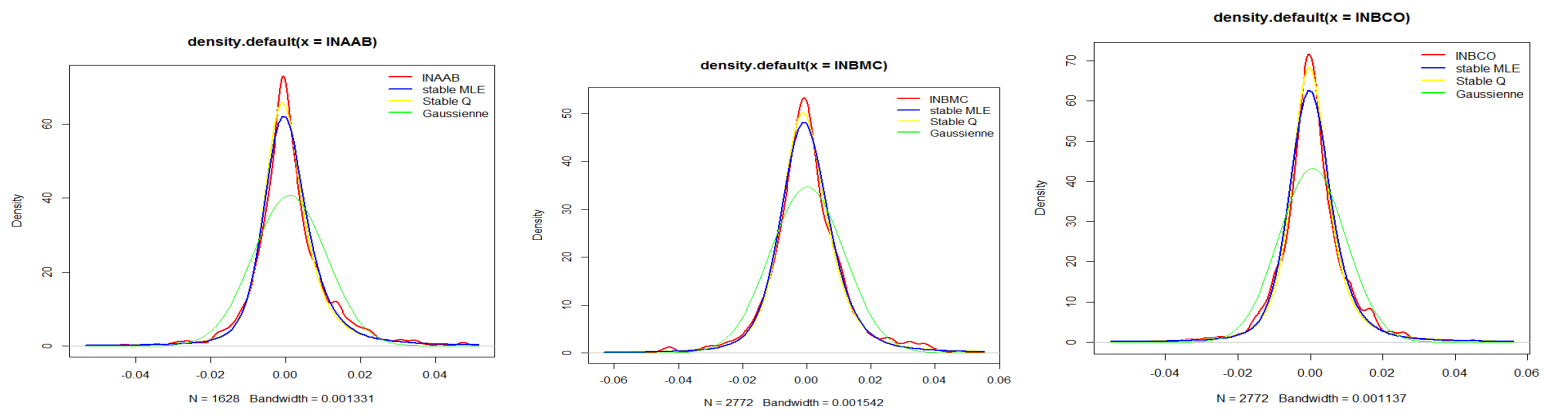

Figure 1. Graphical representation of empirical, alpha stable, and normal distribution of the returns

\section{Fractals}

The Euclidean universe is made of smooth shapes and what is rough, is left out. Mandelbrot was interested in roughness. He coined the term fractal. Fractus in latin means the geometry of what is broken.

A fractal is a geometric shape that can be split up into smaller parts recalling as echoing the shape of a very small scale. The key is to identify regularity in the irregular. The roughness according to Mandelbrot is not an imperfection which disturbs, but it is the essence of many object in nature and economics.

A fractal is a geometrical form that can be split into smaller parties recalling as in echo the form of the whole at a smaller scale. The key consists in locating the regularity in the irregularity. Roughness according to Mandelbrot is not an imperfection that disturbs, but it is the essence of many objects in nature and economy. Fractal geometry seeks to determine these iterative schemes. The variety of fractals is huge but all have some common features. First, they are invariant to scale i.e. the parties respond in echo in a precise and quantifiable formula. The simplest fractals are scale invariant and called auto similar. In this sense, what they show in a certain scale will be similar for all other scales. These fractals are called self-affine. If the fractal zooms in different ways in different places, they are called multifractals.

In addition, Mandelbrot invents the fractal dimension. To make it explicit, imagine that you want to calculate the length of Brittany coast. The more you decrease the size of the rule and the longer the length is increasing. Mandelbrot says the length rise more rapidly than the decrease of the rule. The fractal dimension measures this phenomenon. It is a tool to measure roughness. In fractal geometry, the dimension is relative.

A hazardous way, carried out Mandelbrot, towards the cotton prices at the beginning of the Sixties. According to him, the fluctuations follow power laws. In this sense, the proportion between the most important and weakest variations follows a regular pattern whatever the periodicity observed. Regarding trends, large variations arrive in bursts followed by a long series of small. If you zoom in on a group of important variations, you realize that it is in turn made up of smaller clusters. Zoom in again and you will find smaller concentrations. It is a fractal structure. Jumps are reproduced as in Echo.

Figure 2 shows the variations of the Tunindex since January 1999 until 31/12/2015. At the top we have daily variations, followed by weekly variations and we finish by the monthly variations. Note that the three graphs are similar despite the difference in scale used. We note that financial markets like many objects in nature, are fractals and are generated by the same law or process.

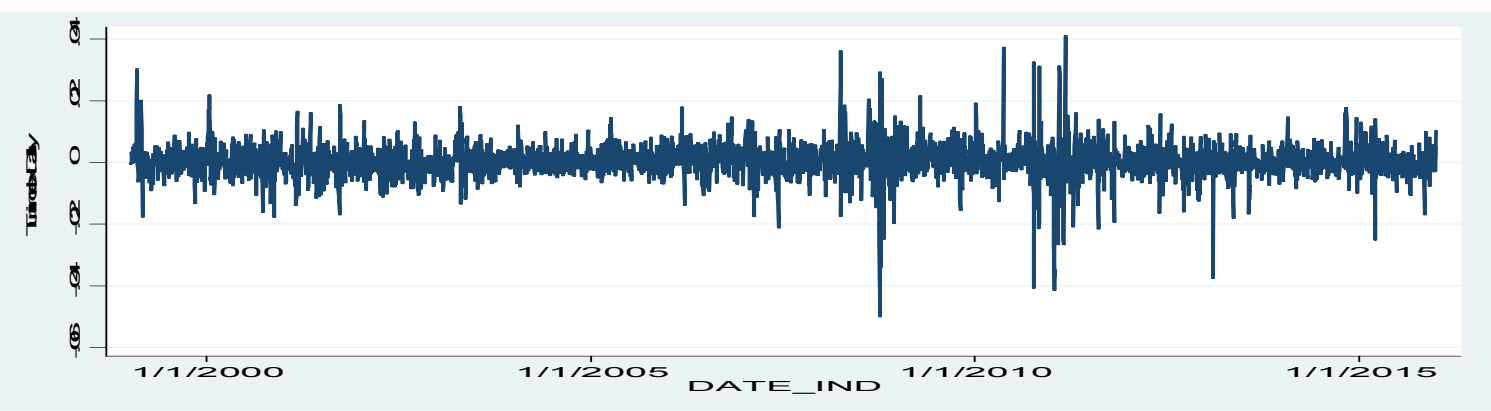



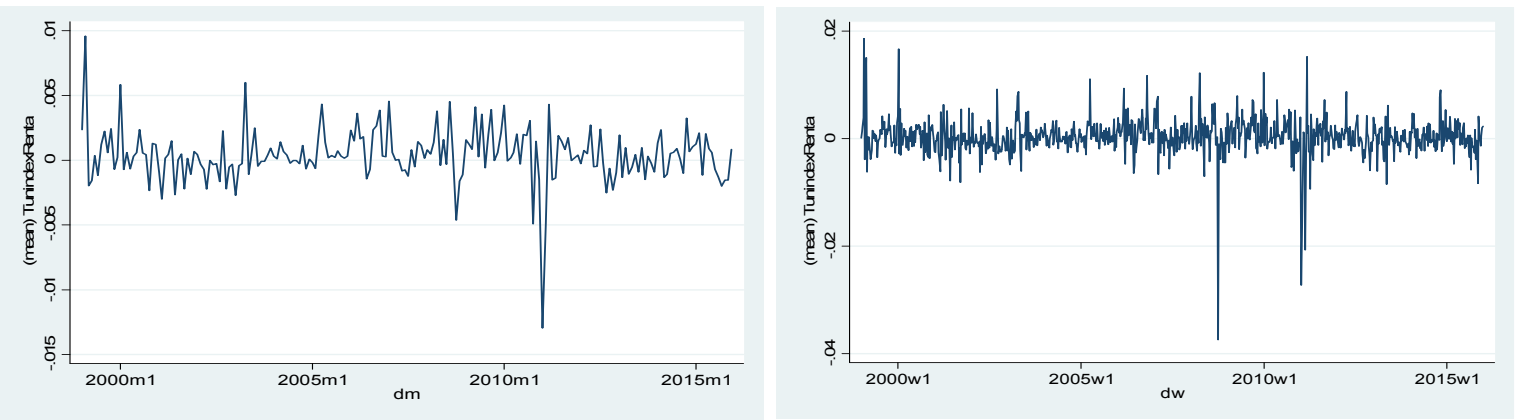

Figure 2. Representation of daily, weekly and monthly returns of the Tunindex since January 1999 until December 2015. The figure is used to highlight the scale invariance and self-similarity

\section{Noah Effect or Discontinuity and Joseph Effect or Persistence}

Two facts emerge from the observation of financial graphics. The first, they fluctuate enormously. These fluctuations are wild. Then they seem to follow irregular trends. We observe two forms of wild variations that Mandelbrot called Noah and Joseph.

In fact, Mandelbrot defines the Noah effect as the fact of having power law distributions with fat tails. The crash as the deluge, is catastrophic but temporary. The figure below shows the Noah effect on the Tunindex in January 2011 during the Jasmin revolution period and in February 2013 in the killig of politician Belaid.

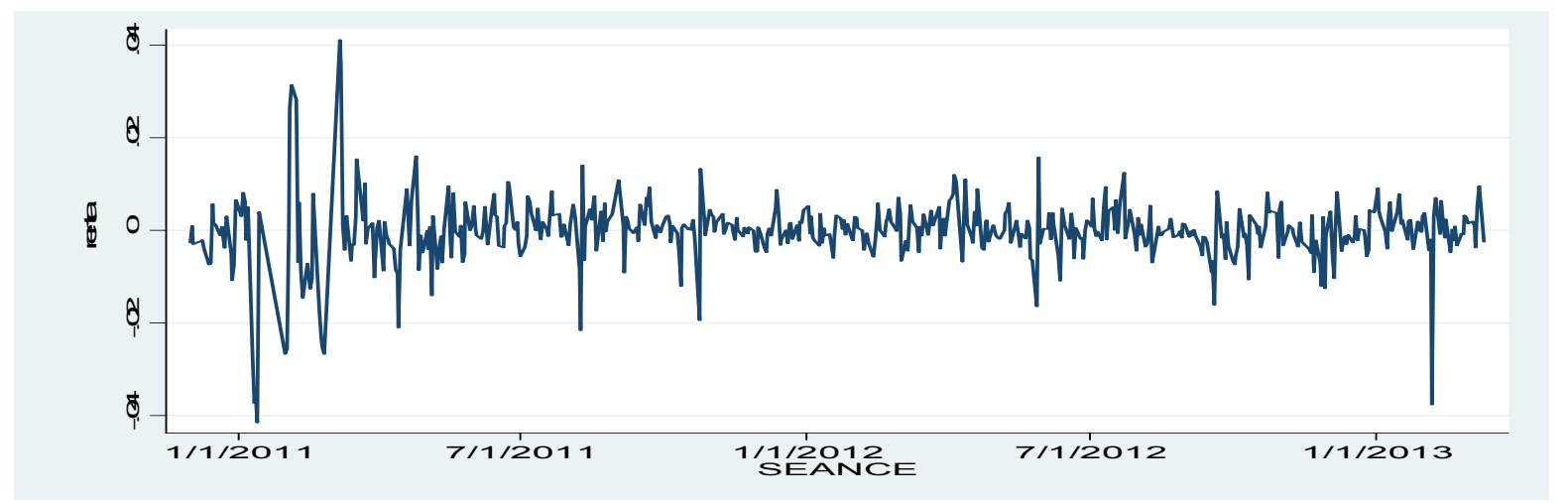

Figure 3. Demonstration of the Noah effect on Tunindex returns.

Mandelbrot discovered the Joseph effect through the study of Hurst on Nile floods. It illustrates the interdependence of price variations or the long memory. The Hurst law stipulates that the difference between the highest and the lowest flows widened to the power $3 / 4$ of the standard deviation. The past influences the random fluctuations of the present. No act is without consequence. Mandelbrot affirms that there exists a relationship between the two effects. Suppose that a bullish tendency is prevailing. After a while, the market will eventually calm down and interruption can be brutal. Thus, we will have a Noah effect produced by a Joseph effect.

With random walk, a Brownian particle released during 1000 seconds will go 100 times further than the one released during 10 seconds. This is the benign form of random. But if this rule is false and if the particle starts to wander beyond the square root of time. Thus, if prices exhibit a form of addiction, illustrated by the fact that when prices take a direction during a session, it will have a greater probability to continue its momentum the next day. The random walk is thus altered, and the Hurst exponent $(\mathrm{H})$ summarizes this tendency to cheat. Therefore, the distance will be proportional to some power of the past time (TH). $\mathrm{H}$ is therefore between 0 and 1 and is no longer equal to 0.5 as in the Gaussian frame (square root).

To measure Noah and Joseph effect, new statistical tools were concocted, some concentrate on the alpha exponent and others on $\mathrm{H}$.

In order to compute the Hurst exponent on the various series of Tunisian indexes returns, we must first carry out unit root tests. To obtain robust results, we use three tests. The first is the ADF test, where the existence of a unit root is the null hypothesis. The second is the PP test that takes into consideration heteroscedasticity and autocorrelation. The third 
is KPSS test, unlike the other two; a null hypothesis reflects the stationarity of the series. To obtain robust results, we use three tests. The first is the ADF test where the existence of a unit root is the null hypothesis. The second is the PP test that in addition considers heteroscedasticity and autocorrelation. The third is the KPSS test that, unlike the two others, the null hypothesis reflects the stationarity of the serie. On the threshold of 5\%, critical values are 0,463 for KPSS test and-2,863 for ADF and PP tests. Table 3 shows that all of the series, except INDAS and INDDI, are stationary, and are integrated of order 1. Furthermore, all of these tests have been renewed for the indexes returns, which were all stationary series. Tests are conducted using the natural logarithm of indexes prices.

Table 3. This table details the three unit root tests in level and in first difference.

\begin{tabular}{lllllll}
\hline & \multicolumn{5}{c}{ Level } & \multicolumn{3}{l}{ First Difference } \\
\cline { 2 - 6 } Indexes & ADF & PP & KPSS & ADF & PP & KPSS \\
\cline { 1 - 6 } Tunindex & -2.358763 & -2.384998 & 2.854851 & -34.14205 & -34.67595 & 0.354549 \\
Tunindex 20 & -0.936073 & -1.038706 & 2.130874 & -26.28620 & -26.75243 & 0.140267 \\
INAAB & -0.476320 & -0.502075 & 3.473258 & -29.58974 & -29.62792 & 0.150098 \\
INAUE & -2.162439 & -2.275932 & 1.011233 & -37.61806 & -37.64714 & 0.599594 \\
INBCO & -0.378689 & -0.349683 & 4.657394 & -38.60498 & -38.60480 & 0.082899 \\
INBMC & -1.019551 & -1.034182 & 1.694096 & -37.20651 & -37.12326 & 0.752172 \\
INDAS & $\mathbf{- 3 . 2 3 9 8 7 5}$ & $\mathbf{- 2 . 9 3 0 3 2 9}$ & $\mathbf{0 . 4 4 8 1 8 7}$ & -36.62303 & -36.69874 & 0.186386 \\
INDBQ & -2.363379 & -2.393542 & -2.363379 & -34.71036 & -34.90900 & 0.332837 \\
INDDI & $\mathbf{- 3 . 4 5 2 4 0 3}$ & $\mathbf{- 3 . 5 5 6 5 5 7}$ & 1.930410 & -36.17168 & -36.27111 & 0.506090 \\
INDIN & -1.764592 & -1.823053 & 2.252216 & -35.83434 & -35.75089 & 1.148334 \\
INDMB & -1.223995 & -1.137822 & 2.814168 & -40.35090 & -40.35047 & 0.586563 \\
INDSC & -2.511204 & -2.586874 & 1.844532 & -39.16714 & -39.25711 & 0.421279 \\
INDSF & -2.473490 & -2.517999 & 2.192190 & -34.37745 & -34.69023 & 0.384431 \\
INPMP & -0.958767 & -0.920031 & 2.198112 & -22.11572 & -22.10255 & 0.113498 \\
INSFI & -2.579169 & -2.741763 & 2.412601 & -37.69046 & -37.73666 & 0.371266 \\
\hline
\end{tabular}

9. Hurst Exponent Estimation

As $\mathrm{H}$ exponent is used to measure the roughness of a series, we can say that the largest the $\mathrm{H}$ the smoother is the time series curve and the more same sign observations will succeed. The long memory means that when the delay increases the autocorrelation function decreases slowly. To measure the long-term dependency, several methods have been applied. Certainly the most used method is named after R/S (range / standard deviation) or analysis of scale variations, which is a nonparametric method. The idea is simple. The joseph effect depends on the events sequence, while Noah effect depends on the relative size of each event. Redistribute data (return series) as a playing card package. Joseph effect should disappear once cards become disorderly scattered. Only the Noah effect remains intact before and after shuffling cards. To perform the test, simply compare the package before and after the reordering. If there is a difference, then it must originate from the long-range dependency in the original data. The precise sequence should have importance in the data and we can measure the level of this importance. If there is no difference then the dependency is negligible.

Thus, R/S or range over STD, measures the excursion of the returns series. When $\mathrm{H}$ exceeds 0.5 , prices will move quickly away from their starting point. If $\mathrm{H}$ is smaller than the Brownian 0.5 , prices will escape less.

$$
R / S=\frac{\underbrace{\operatorname{Max}}_{1 \leq k \leq n} \sum_{j=1}^{k}\left(r_{j-} \overline{r_{n}}\right)-\underbrace{\operatorname{Min}}_{1 \leq k \leq n} \sum_{j=1}^{k}\left(r_{j-} \overline{r_{n}}\right)}{\left[\frac{1}{n} \sum_{j}\left(r_{j-} \overline{r_{n}}\right)^{2}\right]^{1 / 2}}
$$

We can estimate the Hurst exponent as follows $H \sim \frac{\log R / S}{\log n}$ where $\mathrm{n}$ is the observation number. Lo (1991) address critics to the $\mathrm{R} / \mathrm{S}$ method. The latter does not have an asymptotic distribution and is unable to differentiate between the long and the short term. Lo introduced in the denominator a in order to enjoy to appreciate the duality between short- and long memory. 
The aggregate variance method split the series into $\mathrm{m}$ blocks of size $\mathrm{n} / \mathrm{m}, \mathrm{k}$ is the sequence number of each block and we calculate the aggregated series.

$$
Y_{k}^{(m)}=\frac{1}{m} \sum_{t=1+m(k-1)}^{k m} Y(t)
$$

Whereupon we calculate the variance $\mathrm{V}\left(\mathrm{Y}_{\mathrm{k}}^{(\mathrm{m})}\right)$ inside each block and renewed the procedure for different values of $\mathrm{m}$. $\mathrm{H}$ exponent is determined as a result of a regression from the following relation $V\left(Y_{k}^{(m)} \sim C . m^{2 H-2}\right)$.

The absolute value aggregate method is very similar to the aggregated variance method then instead of calculating the variance of each block, we compute the sum of the absolute values. The value of the coefficient $\mathrm{H}$ is given by a regression of the following relation $\left|Y_{-} k^{\wedge}((m))\right| \sim H-1$.

Higuchi (1988) calculated the Hurst coefficient from the fractal dimension D which is equal to $2-\mathrm{H}$.

The residual method is similar to the two previous methods except that we will regress partial series on a trend and the Hurst exponent is obtained from the variance of the residuals. The latter is proportional to $\mathrm{m}^{2 \mathrm{H}}$.

In a parametric framework, ARFIMA process, an extension of ARIMA models can also be used to determine the Hurst exponent, since there is a relationship between the fractional integration parameter, also called memory parameter, and the $\mathrm{H}$ exponent. $\mathrm{d}=\mathrm{H}-1 / 2$.

According to Mignon (1998), the maximum likelihood method is the best estimation technique. However, it remains very costly in execution time due to the inversion of the variances covariances matrix. Nevertheless, the Whittle procedure allows good spectral approximation of the log Likelihood function.

More recently, a new estimation method based on wavelets, which allow a time frequency analysis of a signal, was introduced. The use of the scalogrammes, empirical variance of the wavelet coefficients, turns out more effective than Fourrier methods and very promising for the estimation of the parameter memory Kouamo (2011).

The following table 4 reports all Hurst exponent estimates on the returns series of all indexes coted on the Tunisian Stock Exchange. All calculations were made with R. The results show that the estimates are quite different and this can be explained by the fact that each method has its own calculation algorithm. Nonetheless, all Hurst exponents are higher than 0.5 , regardless of the method used except for the INAAB index estimated with the wavelet method. The estimated coefficients oscillate between 0.6 and 0.7 in most cases and rarely reach 0.8. For example banks index (INDBQ), estimated with ARFIMA model. It is clear that the returns series listed on the BVMT exhibit a persistence phenomenon, which leads to a high probability that similar events will follow each other, and therefore returns series have a long memory. This shows that indexes returns series are smoother than those described by a normal law highlighting a phenomenon of volatility clustering. As returns series are persistent, they consequently have a fractal Brownian motion, or a biased random walk. The presence of noise in the series can be attributed to economic and social changes besides political crisis.

The degree of correlation $C=2^{2 H-1}-1$ is the measure of the effect of an observation on the subsequent ones in the time series. Thus, for the indexes returns series, $\mathrm{C}$ is between 0.148 and 0.319 . Otherwise, the fractal dimension, $D=2-H$, facilitates the analysis of price distributions. Thus the larger is $\mathrm{D}$, the weaker is the accumulated return. The fractal dimension of the indexes return series, range from 1.3 to 1.4. This shows that the series are persistent and observations are positively correlated. This result is similar to those found by Wen et al (2012) on the Shanghai Stock Exchange, and Hacinliyan \& Kandiran (2015) on the Turkish Stock Exchange.

\section{Nonlinearity and Chaos}

Appeared initially in the field of meteorology with Lorenz, Professor of mathematics at MIT in the 1960s, the chaos theory has become very fashionable in the 1970s after a conference entitled " Predictability: Does the Flap of a Butterfly's Wings in Brazil Set Off a Tornado in Texas?". As we have seen with Mandelbrot and hazardous discovery of cotton prices, with Lorenz, chance is also a source of novelties. On introducing, in 1961, the data on his computer, in order to generate numerical simulations for meteorology, Lorenz is eager to drink a coffee and wanting to check some results, he introduced only 3 digits after the decimal point instead of 6 . By coming back, results were extremely different. Difference is so huge that it can only be explained by nonlinearity of equations. So tiny differences could lead to the long to completely different systems, raising the impossibility of making forecasts in the medium and long term Etchecopar (2002). This explains that reliable weather forecasts may not exceed five days. This sensitivity to initial 
conditions is characteristic of chaos. The famous Lorenz butterfly is the illustration of this sensitivity ${ }^{6}$. This figure is also called strange attractor, which has a fractal structure with a fractional dimension that should lie between 2 and 3 . It shows that two paths from very close initial conditions diverge exponentially but will remain on the same attractor.

Hence, Chaos does not mean distress and confusion rather it involves the emergence of an order with lack of prediction Faggini and Parziale (2016). The fractal dimension and the Lyapunov exponent are the two fundamental characteristics of a chaotic process. Their estimation is now possible. In order to justify the calculation of the Lyapunov exponent, the series must come from a stationary and deterministic process. If not, the interpretation of the sign of the exponent does not make sense. The most important step is the determination of the embedding space. These calculations are also required to compute the invariant measures and to achieve the determinism and stationarity tests (Perc (2006)).

In the embedding theorem, Takens says that a large enough dimension permits delay vectors to have the same invariant measurements as the original system.

$$
P(t)=\left(x_{t}, x_{t+\tau} x_{t+2 \tau} \ldots \ldots x_{t+(m-1) \tau}\right)
$$

$x_{t}$ is the value of the time series at time t. The time delay is represented by $\tau$. This vector fully represents nonlinear dynamics when $\mathrm{m}$ is sufficiently large. The embedding theorem ensures that the full knowledge of the behaviour of the system is possible across the time series of any phase. Nevertheless, it is necessary to determine $m$ and $\tau$. To perform it, several methods are described in the non-linear time series literature. In this article, the time delay $\tau$ is determined by the mutual information method while $\mathrm{m}$ will be determined by using the false nearest neighbour method. These two parameters will not only serve to calculate the Lyanupov exponent but also to conduct the determinism test.

\section{BDS Test (Brock, Dechert et Scheinekman, 1996)}

The introduction of nonlinear models in financial time series helped in two ways: to reflect the series dynamics better give and the possibility that the past can influence present random variations. The nonlinearity is the real source of diversity, complexity and variability Fenghua et al (2014).

According to Riane (2015), linear systems are inconsistent with prices variations. In fact, linear variations allow the series to explode or to disappear. This is not possible for asset prices especially with the presence of reservation thresholds. Moreover, linear systems cannot explain volatility clustering phenomena and structural changes.

In order to test the nonlinearity, Brock Dechert Scheinkman (1996) test serves to check whether the variables are independent and identically distributed. The null hypothesis states that the variables are i.i.d. Therefore, this is a preliminary step in seeking a chaotic process. Chaos is a non-linear deterministic process that seems random (Girerd-Potin and Taramasco, 1994). This makes sense only when the hypothesis of i.i.d. returns is rejected. Alexander \& Giblin (1994) states that this test is also robust to detect the presence of non-linearity in the time series. Refined series (without any linear dependency) is examined on dimensions going from 2 to 5 . The test is made on the residues of an autoregressive model. The results show that all values are significant at the $1 \%$ level and allow us to reject the null hypothesis for all values of e/ $\sigma$ et $\mathrm{m}$. Thanks to the findings, we notice that the series are not truly random because some patterns appear more frequently than under a normal law. The indexes returns series in the Tunisian market are non-linear. This result is similar to that of Opong et al (1999) in the British market. Note that the nonlinearity is a necessary but not a sufficient condition for the existence of chaos.

In order to work on time series chaos, it is first necessary to ensure that series has no trend. However, it is known that financial series are characterized by the strong presence of noise. Therefore, it is necessary to remove noise, as it will affect all invariant measures. The objective is then eliminating noise without distorting the nature of the signal Faggini $\&$ Parziale (2016). To do so, we proceed as Riane (2015) and we use the wavelet filtering technique or local projection.

Figure 4 below shows returns series of Tunindex before and after noise treatment. The blue curve is relative to the raw series and the black demonstrates the series without noise. For robustness, different algorithms were used in order to decide on the persistence of each series. The study period varies according to the availability of data and starts for most on 31/05/2008 until 31/12/2015.

\footnotetext{
${ }^{6}$ For more details see Hayek Kobeissi $\quad$ (2012)
} 
Table 4. This table reports the Hurst exponent values calculated over 15 Tunisian indexes.

\begin{tabular}{lllllllll}
\hline Indexes & $\begin{array}{l}\text { R/S Rescaled } \\
\text { Range } \\
\text { Statistic }\end{array}$ & $\begin{array}{l}\text { Corrected } \\
\mathrm{R} / \mathrm{S}\end{array}$ & $\begin{array}{l}\text { Aggregated } \\
\text { variance }\end{array}$ & $\begin{array}{l}\text { aggregated } \\
\text { absolute } \\
\text { value }\end{array}$ & $\begin{array}{l}\text { Peng } \\
\text { Method } \\
\text { Residuals }\end{array}$ & $\begin{array}{l}\text { Higuchi's or } \\
\text { fractal } \\
\text { dimension }\end{array}$ & $\begin{array}{l}\text { Whittle } \\
\text { estimator }\end{array}$ & $\begin{array}{l}\text { wavelet } \\
\text { estimator }\end{array}$ \\
\hline Tunidex20 & 0.6490468 & 0.633526 & 0.5562097 & 0.6161379 & 0.6223015 & 0.6175695 & 0.6591454 & 0.6591454 \\
Tunindex & 0.8114782 & 0.6638367 & 0.6156460 & 0.6861521 & 0.6531251 & 0.6872774 & 0.79770114 & 0.6311485 \\
INSFI & 0.7278959 & 0.6431676 & 0.5284634 & 0.6425367 & 0.6797725 & 0.6129043 & 0.77721647 & 0.571545 \\
INPMP & 0.6078035 & 0.6827694 & 0.6474867 & 0.7784614 & 0.5160254 & 0.5932179 & 0.71339940 & 0.5858119 \\
INDSF & 0.8033428 & 0.6640005 & 0.5864722 & 0.6554048 & 0.6553673 & 0.664561 & 0.80727751 & 0.6077593 \\
INDSC & 0.7301262 & 0.6304419 & 0.6469264 & 0.6748424 & 0.6660278 & 0.6123395 & 0.7438263 & 0.654374 \\
INDMB & 0.7119209 & 0.6217767 & 0.5446568 & 0.6005867 & 0.6021339 & 0.5318635 & 0.74416899 & 0.6090176 \\
INDIN & 0,6032249 & 0.6150507 & 0.5746134 & 0.6192639 & 0.6039186 & 0.5568754 & 0.79863832 & 0.6425527 \\
INDDI & 0.5608664 & 0.6471368 & 0.6419496 & 0.6930925 & 0.6616842 & 0.6576052 & 0.77863908 & 0.6771653 \\
INDBQ & 0.7910295 & 0.646708 & 0.5732085 & 0.6267887 & 0.6503577 & 0.6480756 & 0.80573763 & 0.5866703 \\
INDAS & 0.6858951 & 0.5685628 & 0.5352282 & 0.5959913 & 0.5902887 & 0.5410782 & 0.65740282 & 0.5115013 \\
INBMC & 0.7924578 & 0.566694 & 0.4799549 & 0.5518164 & 0.6209278 & 0.5222312 & 0.79173335 & 0.641944 \\
INBCO & 0.6930065 & 0.6211857 & 0.575022 & 0.6290628 & 0.6067941 & 0.6458559 & 0.73449616 & 0.6275019 \\
INAUE & 0,6092548 & 0.6288755 & 0.5471342 & 0.5911533 & 0.6493879 & 0.5784051 & 0.7658069 & 0.6703701 \\
INAAB & 0.6086475 & 0.6378097 & 0.5470989 & 0.6206584 & 0.5950581 & 0.6438363 & 0.7323112 & 0.4739792 \\
\hline
\end{tabular}

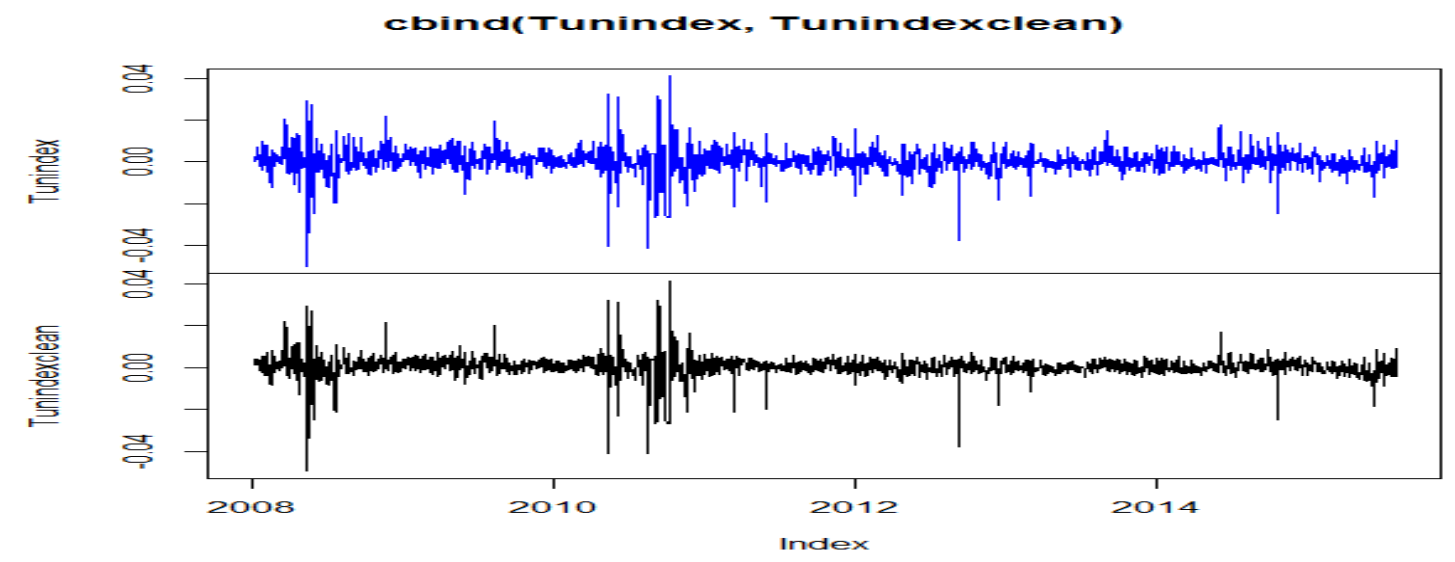

Figure 4. Overview of the Tunindex retuns denoised by local projection technique.

\section{Stationarity of Returns Series}

Conventional tests for detecting stationarity as ADF, KPSS and PP test are not reliable with nonlinear time series. Actually, other tests have emerged. In what follows, we introduce the Theiler window through the time space separation. Indeed, Theiler window allows deleting all close points by temporal nearness. It is the period of time from which the time space separation curves are stable.

The following figure is related to Tunindex, it proves that the Theiler window is set at 2 . Maximum 2 trading days are needed for returns to become stationary ${ }^{7}$. Beyond this period of time, temporal proximity has no effect on the probability of two points being close.

This figure illustrates the number of days required for a series to become stationary. It is the Theiler window.

\footnotetext{
${ }^{7}$ Very similar figures related to the other indexes available from the author upon request.
} 


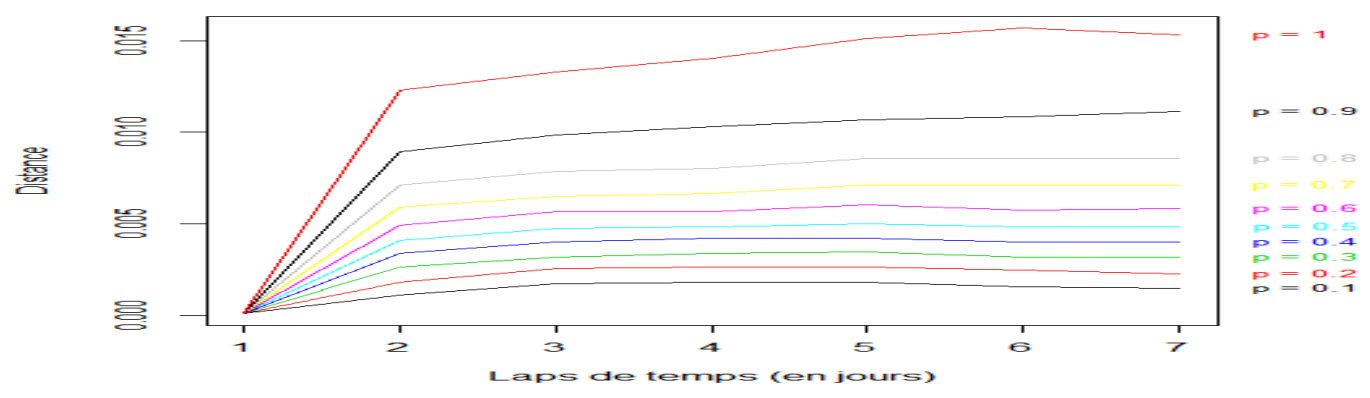

Figure 5. The tunindex time space separation

$\mathrm{m}$ is the embedding dimension. Column 1 shows the distance e between two points. This distance is expressed according to the empirical STD. The results are given to e equals $0.5,1,1.5$ and 2 standerd deviations. The following columns give the test values for all considered indexes. The critical value is 1.96 for a $5 \%$ confidence level.

Table 5. This table reports the results of the BDS test on daily returns on the Tunis stock exchange from 5/30/2008 until $31 / 12 / 2015$

\begin{tabular}{|c|c|c|c|c|c|c|c|c|c|c|c|c|c|c|c|c|}
\hline $\mathrm{e} / \sigma$ & $\mathrm{m}$ & Tunindex & Tunindex 20 & INSFI & inpmp & Indsf & Indsc & Indmb & Indin & Inddi & Indbq & Indas & Inbmc & Inbco & Inaue & Inaab \\
\hline 0.5 & 2 & 52.090 & 38.2537 & 44.327 & 21.0923 & 53.0500 & 46.0098 & 50.0929 & 48.873 & 43.494 & 53.375 & 36.143 & 46.465 & 44.042 & 52.986 & 31.884 \\
\hline 0.5 & 3 & 60.478 & 45.5143 & 52.456 & 25.9548 & 62.7717 & 53.7640 & 59.8270 & 58.865 & 50.96 & 64.102 & 45.968 & 55.762 & 52.511 & 66.480 & 37.201 \\
\hline 0.5 & 4 & 67.377 & 49.6650 & 57.344 & 29.2104 & 71.0096 & 59.5574 & 65.0450 & 65.688 & 55.653 & 73.190 & 52.568 & 62.629 & 58.176 & 76.324 & 40.647 \\
\hline 0.5 & 5 & 75.853 & 53.4064 & 64.113 & 33.9016 & 81.2647 & 67.5897 & 72.2042 & 75.055 & 61.478 & 84.289 & 59.895 & 71.547 & 65.776 & 90.509 & 45.515 \\
\hline 1 & 2 & 40.711 & 29.0873 & 35.763 & 17.6065 & 42.1594 & 38.5147 & 36.2165 & 38.080 & 35.740 & 43.210 & 26.268 & 37.804 & 35.444 & 42.123 & 25.551 \\
\hline 1 & 3 & 42.392 & 30.6546 & 37.672 & 19.3152 & 44.4996 & 40.8932 & 38.2974 & 40.292 & 37.818 & 46.089 & 29.462 & 39.946 & 37.945 & 46.404 & 27.173 \\
\hline 1 & 4 & 42.882 & 30.7753 & 38.512 & 19.8101 & 45.8123 & 41.8807 & 38.7970 & 41.171 & 38.345 & 47.965 & 30.729 & 40.915 & 38.633 & 48.510 & 27.136 \\
\hline 1 & 5 & 43.759 & 31.0966 & 40.011 & 20.8378 & 47.5873 & 43.6975 & 40.1008 & 42.918 & 39.412 & 50.398 & 32.184 & 42.712 & 39.799 & 51.466 & 27.566 \\
\hline 1,5 & 2 & 37.824 & 26.0647 & 34.758 & 15.1867 & 38.5835 & 36.9830 & 32.7079 & 37.429 & 35.467 & 40.093 & 23.873 & 36.989 & 33.420 & 38.795 & 23.808 \\
\hline 1,5 & 3 & 37.626 & 26.2321 & 35.122 & 15.8948 & 38.4727 & 37.6697 & 32.9433 & 37.886 & 35.947 & 40.105 & 25.809 & 37.328 & 33.977 & 40.471 & 24.459 \\
\hline 1,5 & 4 & 36.387 & 25.2766 & 34.386 & 15.7074 & 37.4185 & 37.0044 & 31.9836 & 37.189 & 35.158 & 39.228 & 25.893 & 36.781 & 33.268 & 40.602 & 23.814 \\
\hline 1,5 & 5 & 35.437 & 24.4944 & 34.141 & 15.7143 & 36.7758 & 36.7373 & 31.5626 & 36.951 & 34.615 & 38.795 & 26.024 & 36.644 & 32.750 & 40.901 & 23.234 \\
\hline 2 & 2 & 37.294 & 24.4709 & 35.060 & 16.9201 & 37.7135 & 36.3768 & 32.2566 & 38.539 & 35.761 & 38.884 & 23.402 & 36.928 & 33.317 & 36.668 & 24.142 \\
\hline 2 & 3 & 36.173 & 24.1534 & 34.622 & 16.6945 & 36.4477 & 36.2251 & 31.8247 & 38.096 & 35.332 & 37.600 & 24.692 & 36.542 & 32.811 & 37.128 & 23.684 \\
\hline 2 & 4 & 34.147 & 22.9310 & 33.108 & 16.1029 & 34.4726 & 34.8521 & 30.2093 & 36.763 & 33.909 & 35.644 & 24.229 & 35.487 & 31.283 & 36.491 & 22.586 \\
\hline 2 & 5 & 32.553 & 21.8075 & 32.072 & 15.6390 & 32.9988 & 33.7879 & 29.0980 & 35.713 & 32.662 & 34.183 & 23.811 & 34.618 & 29.973 & 35.834 & 21.589 \\
\hline
\end{tabular}

\section{Optimal Delay}

An optimal delay must meet two criteria. The first criterion, it should be wide enough so that the value of the variable measured at $t+\tau$ is relevant and significantly different from that measured at $\mathrm{t}$. It is worth noting that a short delay can always be offset by an important dimension $\mathrm{m}$. Second, it should not be beyond the time required for the system to lose from memory its original state (Matjaz (2006)). This last condition leads us to determine $\tau$ from the autocorrelation function defined as $a(\tau)=\frac{1}{T+1} \sum_{t=0}^{T} x_{t} x_{t+\tau}$. The optimal $\tau$ is determined by the time at which the auto correlation function falls below 1/e. Even though, this works very well with linear statistics, it gives skewed results for nonlinear series. This lead us to use the first minimum of the mutual information function (Fraser Swinney 1986), which represents the dependence degree in a probabilistic sense.

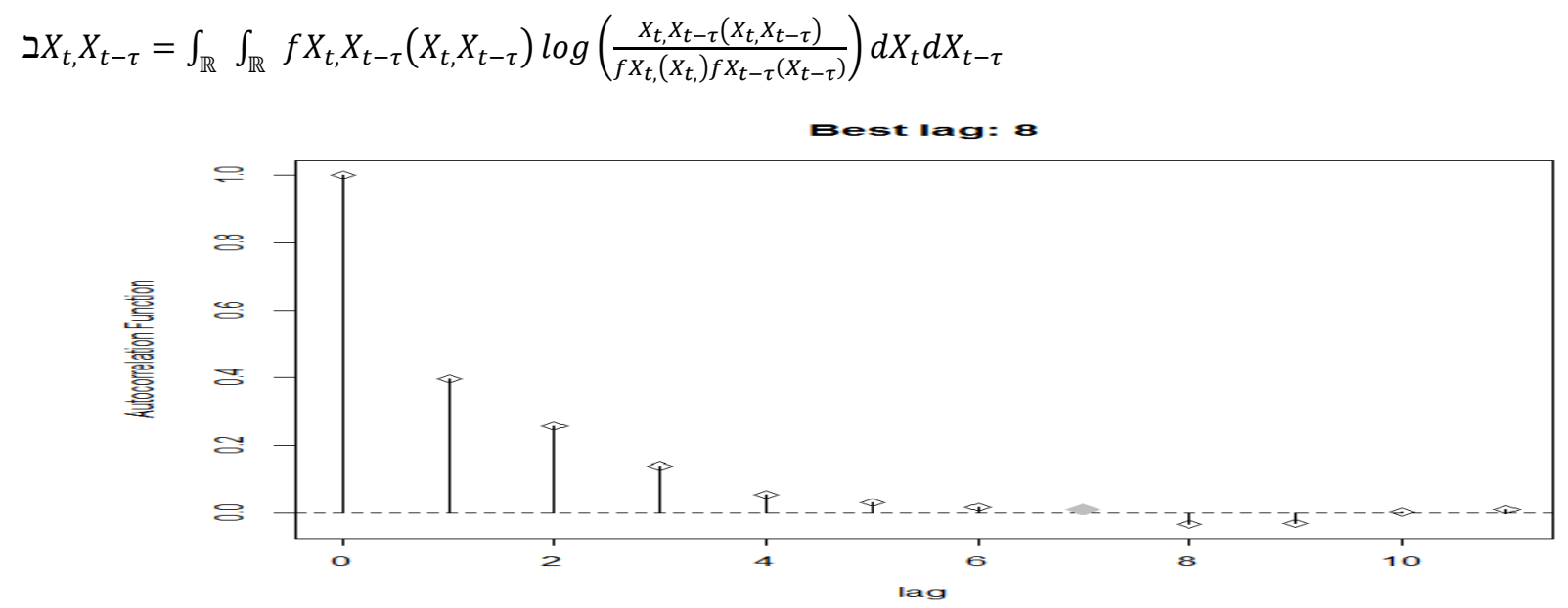

Figure 6. Determination of the Tunindex optimal delay using mutual information method. 


\section{Embedding Dimension $m$ Using the False Nearest Neighbour Method}

To determine the embedding dimension $\mathrm{m}$, we have to find the dimension from which the number of false neighbours is zero. We must reduce the number of similar values close in time (false neighbours). The figure below, allows us to conclude that the embedding dimension is 9 for the Tunindex. Indeed, it is clear that from this dimension, the percentage of false neighbours falls to 0 .

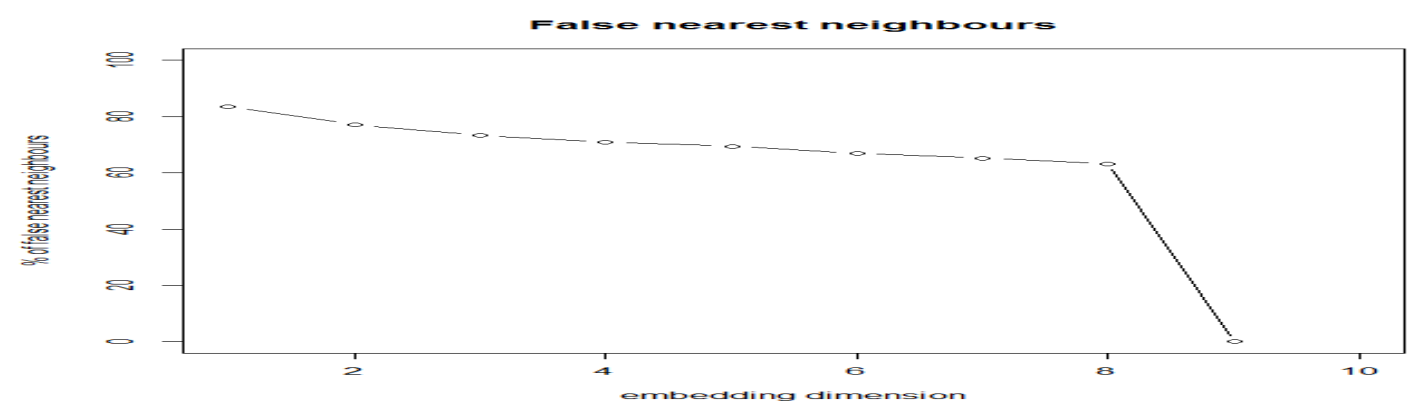

Figure 7. Determination of the Tunindex embedding dimension using the false nearest neighbour

The calculation was done for all other indexes, the results are summarized in table 6 below. Once the embedding dimension and the delay were calculated, and the phase space reconstructed, we can calculate the Lyapunov exponent.

\section{Lyapunov Exponent Calculation}

The discovery of deterministic systems leads to the existence of erratic behaviours similar to those of white noise Sandri (1996). The statistical approaches seeking to detect determinism include the embedding dimension and the Lyapunov exponent. The distance between the two trajectories evolves over time according to $\mathrm{e}^{\lambda} \cdot \lambda$ is the Lyapunov exponent.

It is essentially a tool measuring the divergence of two initially close trajectories.

$$
\delta_{n} \approx \delta_{0} e^{\lambda T}
$$

$\delta_{0}$ is the initial distance, $\delta_{n}$ is the distance after time $T$. The exponent is estimated using the slope obtained from the following linear regression

$$
S_{(T)}=\lambda T \approx \log (\delta(t) / \delta(0))
$$

Thus, it induced the low predictive power. On the one hand, if the maximum Lyapunov exponent is positive, the system is chaotic. On the other hand, if it is negative, the system is regular. There are as many $\lambda$ as dimensions. They can be ranged from the largest to the smallest forming the Lyapunov exponent spectrum. They give an idea about the attraction or the stretching exerted on the system by each dimension (Alexendre (1994)).

The following table contains the measures of the delay time, the embedding dimension as well as the Lyapunov exponent for all indexes traded on the Tunisian stock exchange.

The results indicate that the largest Lyapunov exponent is positive for all indexes, indicating the presence of a chaotic attractor. This shows the low predictability of the system. Note that INBMC and INPMP indexes have got the highest exponent and are therefore the most unpredictable. These results are similar to those found on the Moroccan market, by Riane (2014). However, the confirmation of the existence of a chaotic attractor is only possible after performing the determinism test.

\section{Determinism Test}

This test allows us to check the existence of a deterministic trend in the structure of a time series. It permits to determine the most appropriate model to the data, namely a deterministic chaos or an irregular random model that looks like chaos but originates in a stochastic system. The objective is to verify the presence of a rule behind a dynamic process. The test seeks to know if the images of two near points are also close together?

Indeed, the approach is based on the observation of the tangent to the path generated by a deterministic system. This system is a function of the position in the phase space. When the system is deterministic, all tangents to the trajectory in a given phase space have similar orientations, Xiaohua et al (2016). In fact, a deterministic time series always finds its 
origins in a deterministic process that can be described by a set of ordinary differential equation of first order.

Table 6. This table reports the delay and the embedding dimension estimated respectively by the average mutual information and the false nearest neighbour methods

\begin{tabular}{llll}
\hline & $\tau$ & $\mathrm{m}$ & $\Lambda$ \\
\hline Tunindex & 4 & 9 & 0.2247885 \\
TUN20 & 3 & 9 & 0.274687 \\
INSFI & 5 & 9 & 0.2040836 \\
INPMP & 2 & 9 & 0.2939102 \\
INDSF & 2 & 9 & 0.3074937 \\
INDSC & 4 & 9 & 0.1941999 \\
INDMB & 5 & 8 & 0.2550163 \\
INDIN & 2 & 11 & 0.1970612 \\
INDBQ & 6 & 11 & 0.1790775 \\
INDAS & 3 & 13 & 0.03157461 \\
INBMC & 2 & 11 & 0.2904533 \\
INBCO & 5 & 9 & 0.2083435 \\
INAUE & 5 & 10 & 0.2201911 \\
INAAB & 4 & 15 & 0.2441523 \\
\hline
\end{tabular}

The solution of this system exists and it is unique. In this context, the vector field at each point of the phase space can be drawn easily, Matjaz (2006). The reconstructed phase space must be divided into boxes of same size and embedding dimension. Each pass of the trajectory by a box, a vector is assigned. Every time $\mathrm{i}$ the trajectory passes through the $\mathrm{k}^{\text {th }}$ box a vector named $\mathrm{e}_{\mathrm{i}}$ is assigned and its direction is determined from the entry point and the exit point in this box. In fact, this is the average path direction through the box. Approximation of the vector $\mathrm{v}_{\mathrm{k}}$ in the $\mathrm{k}^{\text {th }}$ box is none other than the average vector of all passes according to the following equation:

$$
V_{k}=\frac{1}{P_{K}} \sum_{i=1}^{P_{K}} e_{i}
$$

With $P_{K}$ is the number of all passages in the $\mathrm{K}^{\text {th }}$ box. By replicating this at all boxes, we get an approximation of the system direction. If the series is deterministic, the resulting vector must be made by unit vectors. MATJAZ (2006) defines a measure of determinism as:

$$
K=\frac{1}{A} \sum_{k=1}^{A} \frac{\left(V_{k}\right)^{2}-\left(R_{k}^{m}\right)^{2}}{1-\left(R_{k}^{m}\right)^{2}}
$$

A is the number of occupied boxes.

$\mathrm{R}_{\mathrm{k}}^{\mathrm{m}}=\mathrm{c}_{\mathrm{m}} \mathrm{P}^{-\frac{1}{2}}$, with $\mathrm{c}_{\mathrm{m}}$ is a constant which depends on the embedding dimension. We conducted determinism test for Tunindex, approximating the vector in the reconstructed space with $\mathrm{m}=9$ and $\tau=4$. The attractor is shown in the figure 8 below. For Tunindex, relative factor of determinism $\mathrm{k}$ is 0.5524 . It is therefore different from 1 . It follows that the series is not deterministic. This test has been extended to all other indexes and results do not confirm the existence of a chaotic system. This makes the conclusions drawn from the Lyapunov exponent inappropriate. 


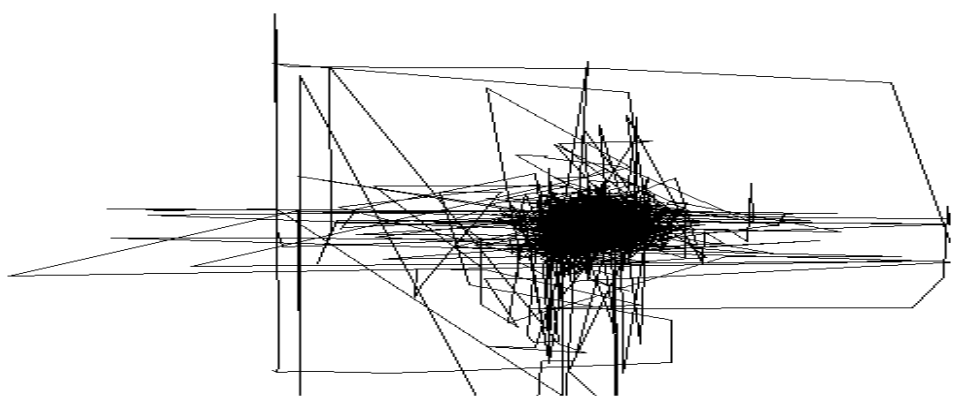

Figure 8. Attractor of IBVMT

Determinism test can also be carried out according to the Kaplan (1994) method. Let $\delta_{i, k}=\left|X_{i}-X_{k}\right|$ be the distance between two points $X_{i}, X_{k}$ and $\epsilon_{i, j}=\left|X_{i+1}-X_{j+1}\right|$ is the distance between their images. $e(r)=\overline{\epsilon_{l, j}}$ pour $r<\delta_{i, k}<$ $r+\Delta r$ represents the average distance. Kaplan demonstrates that when the system is determinist $\lim _{r+\Delta r \rightarrow 0} e(r)=0$. While it tends to $\varepsilon$ when the process is stochastic. The test is based on the identification of substitution series with the same properties as the ones of the original serie and calculate statistic $E=\bar{\epsilon}_{i, j}$. A comparison between the results of the original and reconstructed series will be made. If $\lim _{r \rightarrow 0} E=0$, then the series is deterministic. The figure 9 below highlights $\mathrm{r}$ in the $\mathrm{x}$-axis and the statistics $\mathrm{E}$ in Y-axis. The original series in plotted points while the randomly reconstructed series are in boxeplots for embedding dimensions ranging from 1 to 9.
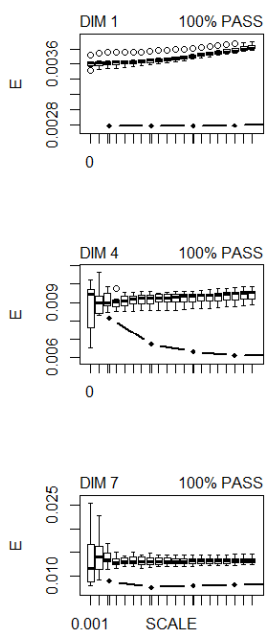
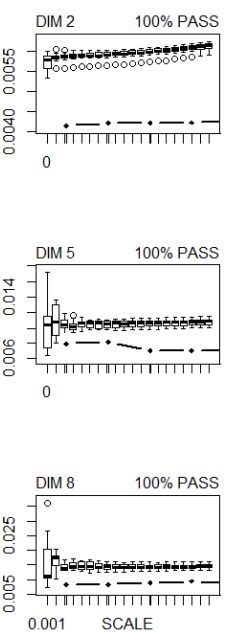
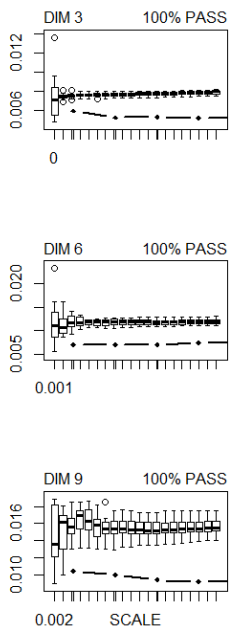

Figure 9. Determinism Test of Tunidex. E statistics is shown in dotted lines for the original series and box plot for alternative series

Except for dimensions 3 and 4, we note a difference in statistics $\mathrm{E}$ between original and surrogate series when $\mathrm{r}$ tends to 0 . Furthermore, E does not exponentially grow with $\mathrm{r}$. So, we definitely reject the hypothesis of a deterministic chaos for the Tunindex returns series from May 2008 until December 2015.

\section{Conclusion}

In this article, we performed the necessary analysis to detect the presence of chaos in Tunisian indexes returns series. The returns distributions exhibit fat tails and are rather fitted by Levy distributions than by Gaussian distributions. Hurst exponent was calculated using different algorithms and has confirmed the persistence phenomena. The BDS test shows that the returns dynamic is non-linear, a necessary but not sufficient condition to deterministic chaos. The Lyapunov exponent is positive for all series showing sensitivity to initial conditions. However, we conclude that a positive Lyapunov exponentc could certainly not be interpreted as the evidence of chaos presence. Indeed, Faggini and Parziale (2016) noticed that chaos theory does not have the same impact on physical sciences and economics. This can be attributed to the existence of noise, to the small sample size and to the lack of robustness tests for chaos in financial data. 
These are the product of complex processes including institutional changes and variations in monetary regimes besides of political crises. Nonlinearity and the instability structure of data require the development of new filtering techniques. In reality, the combination of Artificial Neuron Network with the wavelet analysis may be of particular interest.

\section{References}

Alexander, C., \& Giblin, I. (1994). Creating Order Out of Chaos, Risk Magazine, 7(6), 71-76.

Blank, S. C. (1991). Chaos in futures markets: a nonlinear dynamically analysis. J. Futures Mark 11, 711-728. https://doi.org/10.1002/fut.3990110606

Brock, W., Dechert, W., Scheinkman, J., \& LeBaron, B. (1996). A Test for Independence Based on the Correlation Dimension, Econometric Reviews, 15, 197-235. https://doi.org/10.1080/07474939608800353

DuMouche, W. H. (1971). Stable Distributions in Statistical Inference PhD dissertation Department of Statistics Yale University

El Haddad, M. Y., \& Essafi, S. (2016). Chaotic dynamics: a nonlinear analysis of stock returns series-Case of the Casablanca Stock Exchange, International Journal of Innovation and Applied Studies, 15(1), 183-190.

Etchecopar, P. (2002). Cégep de Rimouski, Quelques éléments sur la théorie du chaos, Disponible sur le Site du Saut Quantique, URL: www.apsq.org/sautquantique/telechargement/ chaos.pdf

Faggini, M., \& Parziale, (2016). More than 20 years of chaos in economics, Mind \& Society, 15(1), 53-69. https://doi.org/10.1007/s11299-015-0164-1

Fraser, S. Independent Coordinates for strange Attractors from Mutual Information. Physical Review A, 33, 1134-1140. https://doi.org/10.1103/PhysRevA.33.1134

Girerd-Potin, I., \& Taramasco, O. (1994). Les rentabilités à la bourse de Paris sont-elles chaotiques? Revue économique, 45(2), 215-238. https://doi.org/10.1016/0167-2789(88)90081-4

Hacinliyan, A. S., \& Kandiran, E. (2015). Fractal Analysis of Stock Exchange Indices in Turkey, Online Academic Journal of Information Technology, 6(18).

Hayek, K. Y. (2012). Multifractal Financial Markets: An Alternative Approach to Asset and Risk Management, Springer Briefs in Finance

Herlin, P. (2010). Finance: le nouveau paradigme Comprendre la finance et l'économie avec Mandelbrot, Taleb, EYROLLES.

Higuchi, T., (1988). Approach to an Irregular Time Series on the Basis of the Fractal Theory, Physica, 31D, 277-283.

Hołyst, J. A., Żebrowska, M., \& Urbanowicz, K. (2001). Observations of deterministic chaos in financial time series by recurrence plots, can one control chaotic economy?, The European Physical Journal B, 20(4), 531. https://doi.org/10.1007/PL00011109

Kouamo, O. (2011). Analyse des séries chronologiques à mémoire longue dans le domaine des ondelettes, thèse de doctorat TELECOM ParisTech

Lin, W. (2014). Finance Forecasting in Fractal Market Hypothesis, Master in Applied Statistics, Örebro University.

Lo Andrew, W. (1991). Long -Term Memory in Stock Market Prices, Econometrica, 59(5), 1279-1313. https://doi.org/10.2307/2938368

Mandelbrot, B. (2009). Une approche fractale des marchés Risquer perdre et gagner, Odile Jacob

Matjaz, P. (2006). Introducing Nonlinear Time Series Analysis In Undergraduate Courses, Fizika, 15(2), 91-112.

McCulloch, J. (1986). Simple consistent estimators of stable distribution parameters. Communications in Statistics Simulation and Computation, 15, 1109-1136. https://doi.org/10.1080/03610918608812563

McKenzie, M. D. (2001). Chaotic behavior in national stock market indices. Global Finance Journal, 12(1), 35-53. https://doi.org/10.1016/S1044-0283(01)00024-2

Mignon, V. (1998). Méthodes d'estimation de l'exposant de Hurst- Applications aux données financières, économie et prévision, 132(1), 193-214.

Opong, K. K., Mulholland, G., Fox, A. F., \& Farahmand, K. (1999). The Behavior of Some UK Equity Indices: An Application of Hurst and BDS Tests. Journal of Empirical Finance, 6, 267-282. https://doi.org/10.1016/S0927-5398(99)00004-3

Perc, M. (2006). Chaos promotes cooperation in the spatial prisoner's dilemma game, Europhysics Lett., 75(6), 841-846. 
https://doi.org/10.1209/epl/i2006-10217-3

Riane, N. (2015). Etude de la dynamique non-linéaire des rentabilités de la bourse de Casablanca. University Library of Munich, Germany.

Sandri, M. (1996). Numerical Calculation of Lyapunov Exponents, The Mathematica Journal, 6(3).

Sewell. M. (2008). Chaos in financial markets, working paper

Song, X. H., Niu, D. X., \& Zhang, Y. L. (2016). The Chaotic Attractor Analysis of DJIA Based on Manifold Embedding and Laplacian Eigenmaps, Hindawi Publishing Corporation Mathematical Problems in Engineering, 2016.

Taleb, N. N. (2010). Le Cygne noir la puissance de l'imprévisible, Les Belles Lettres.

Touba, S. (2014). sur l'estimation des parametres des lois stables, Université Mohamed Khider Biskra, PhD thesis.

Wen, F. H., Li, Z., Xie, C. H., \& David, S. (2014). Study on the fractal and chaotic features of the Shanghai Composite Index, Fractals, 20(2), 133-140. https://doi.org/10.1142/S0218348X12500120

Wen, X., Wei, Y., \& Huang, D. (2012). Measuring contagion between energy market and stock market during financial crisis: A copula approach. Energy Economics, 34(5), 1435-1446. https://doi.org/10.1016/j.eneco.2012.06.021

\section{Copyrights}

Copyright for this article is retained by the author(s), with first publication rights granted to the journal.

This is an open-access article distributed under the terms and conditions of the Creative Commons Attribution license which permits unrestricted use, distribution, and reproduction in any medium, provided the original work is properly cited. 